\title{
The Non-verbal Communication in English Classroom Teaching
}

\author{
Di Zhang \\ The Foreign Language Department \\ Linyi University \\ Linyi, Shandong, 276000, China
}

\begin{abstract}
As a new and exciting science, however, the nonverbal communication takes a significant place in the English classroom teaching. This thesis starts from the definitions of the Non-verbal communication and focuses on some usages of the Non-verbal communication in English classroom teaching on the basis of the current situation of English teaching, such as the use of body language, space language, environment language. Though using of such strategies and techniques, teachers and students' ability of non-verbal communication have been greatly improved.
\end{abstract}

Keywords-non-verbal communication; English classroom teaching; body language;

\section{INTRODUCTION}

Naturally, everyone attaches great importance to the effect of expressing himself in language, but they usually pay little attention to the function of Non-verbal communication. The study on NVC just started after World War II. Most linguists agreed that at first human beings communicated with each other through body language such as bodily movement, gestures, postures, facial expressions, eye contact, and touch and so on, rather than verbal means. The history of the use of nonverbal signals is far longer than the use of verbal means. In the 1950s, nonverbal communication made a breakthrough development. In the 1960s the study of the NVC developed to a new stage, at which man's different gestures were studied. Since 1980s the study on NVC has further developed. Some Chinese scholars began to study it from many different dimensions like linguistics, architecture, art, sociology, etc. Abererombic says: "We speak with our vocal organs, but we converse with our whole body."(Cited in Bijiwan 1995:72) Everyday, people conduct a lot of Nonverbal behaviors such as performing facial expressions, postures and action, consciously and unconsciously. And these signals convey different messages about us to others consciously or unconsciously. Many studies have revealed some important facts about our use of Non-verbal communication.

There are scores of definitions that researchers and scholars use to refine Non-verbal communication. According to Mark Knap (1980:18) the term non-verbal communication refers to non-verbal behavior that people perform with the value of message, and the signals to which meaning will be attributed. It can be used to describe all human communication events that transcend spoken or written words. Bur goon and Sain (cited in Malandra, 1989:7) show that "NVC is the qualities or behaviors known to all in a community without the use of words and such qualities or behaviors are intentionally given by the speaker and consciously received and responded by the listeners". According to James C and Steverk, NVC is a process of one person stimulating meaning in the mind of another person non-verbally. The linguist Samovar (2000) has made a great effort to interpret the term. He proposes "NVC involves all those nonverbal stimuli in a communication setting that are generated by both the variety of ways without the use of verbal codes. It is both intentional and unintentional."

\section{THE USE OF NON-VERBAL COMMUNICATION IN ENGLISH CLASSROOM TEACHING}

So far, it has come to know the importance and necessity of cultivating the English teacher's nonverbal communicative competence in secondary school. Teachers should not only focus on verbal behavior or cultural differences in verbal forms. Students and teachers should also learn nonverbal behaviors used in foreign cultures, or some of the mistakes like pragmatic failures might be made in communication. In order to get a better understanding of nonverbal cues applied in the classroom, the paper would like to discuss the use of nonverbal communication in English teaching, in the aspects of body language, space language, and environmental language.

\section{A. Body Language in English Classroom Teaching}

The study of how movement communicates is called body language, or kinesics. In general, kinesics cues are those visible body shifts and movements that can send messages about (1) our attitude toward the other person (standing faceto-face with a friend (direct body orientation), or leaning forward may show that we are relaxed), (2) our emotional state (tapping on the table or playing with coins can mean we are nervous), and (3) our desire to control our environment (motioning someone to come closer means we want to talk to him or her). Scholars suggest that we can make as many as 700,000 distinct physical signs. The purpose is simply to call the attention to the idea that while all people use movements to communicate, culture teaches us how to use and interpret these movements.

Body language, as the most frequent use of nonverbal cues in the class, can lead to the level of effectiveness of teaching directly. Teachers' mile, nod and pat of students' shoulders can indicate praise, while frown, head-shaking and confusing 
look can mean "no", and students' body language can convey their affection to the teacher and their attitudes toward the courses that they learn and toward school's rules. Here the paper would like to look into some of the more significant movements of kinesics from these three parts in great details. They are facial expressions, eye contact, as well as general appearance and dress of teachers.

1) The Use of Facial Expressions in English Classroom Teaching

Facial expression between teachers and students is one of the most important types of nonverbal signals in the classroom, and face cues are the first information that we give to or receive from others. Researches show that children judge whether the overall meaning of a nonverbal signal is friendly or negative primarily from the facial expressions and eye contact.

In English class, the lively facial expressions can promote a supportive and non-threatening classroom atmosphere, which aids students' positive attitudes and corresponding achievement. When the teacher raises a question in English, an expectant expression she shows can encourage students to think carefully and answer actively. If the student's answer is correct, especially when the question is a little more difficult, a pleasantly surprised look on the teacher's face with nod between whiles could make the student wild with joy; if the student's answer is wrong or not completely right, the teacher can shake her head gently or use degree of liprounding to hint the student to find the right answer. Sometimes an unconscious frown can make sensitive student correct his answer immediately. It is much better than just saying "No" or "Wrong" by doing so. It can protect the students' proper pride.

In addition, a teacher should often smile in class; a smiling teacher is thought to convey warmth and encouragement in all cultures. In other words, if a teacher smiles frequently, she will be perceived as more likable, friendly, warm and approachable. Smiling is often contagious and students will react favorably and learn more.

2) The Use of Eye Contact in English Classroom Teaching

Eye contact is one of the most important types of nonverbal signals in the classroom. There are two kinds of eye contact that the teacher often uses in class. One is looking around. Looking around is a very useful eye contact in classroom teaching. It can be used to get the students' attention, to encourage students to thinking carefully, and to find the students who get or nearly get the answer so as to put question to. It can also be used as a means in classroom control. But teachers should pay attention to the following three factors when using it:

First, looking around should obey certain route in classroom. It cannot be disorderly and unsystematic. Secondly, looking around should "touch" every corner of the classroom, but it's unnecessary to look at every student clearly, or it will waste too much teaching time. Thirdly, the frequency of the teacher's looking around can't be too high, or the students may feel the teaching content is untrue and the teacher is no serious.
Another kind of eye contact is looking attentively or gaze. When the teacher criticizes the student's bad behavior, his/her eyesight should put on the triangle part of the students' face. By doing so, the teacher will be impressed as serious, careful and honest. The gaze region used in the teaching process is also a triangle on the students face. But this triangle is an inverted one. This kind of gaze can form a warm, natural atmosphere. When the teacher talked to a student separately, the gaze region used is an enlarged triangle. This kind of gaze can form a close relationship.

According to Harrison (1974), besides "looking", eye can serve to seek, feedback or to monitor fellow interactions and to exercise control over communication channel. Eyes also infer relationship between teachers and students in classroom, particularly dominance or submission, liking or disliking. When a teacher looks at every student in the classroom or avoids looking at students, he/she conveys the attitude of intimacy, concern, depression or indifference. Teachers often look at students, seeking for signals to determine whether students are paying attention to or understanding what they have said, and to determine whether they should go on with talk or not, which indicate they expect responses from students. Teachers often watch their students carefully for the sign of fatigue, boredom, confusion, or enthusiasm for all these things will be communicated to the teachers through their eyes during the teachers' presentation. Looking directly is thought to be monitoring for promoting attentiveness involvement, and avoiding eye contact keeps channels of communication closed when students do not wish to answer the question; students who wish to answer or know the answer generally send out a message by eye contact, which says, "I'm open to communication".

English class may be a little more special than other classes, because English class requests students to talk more with teachers, especially, in English. Many students comment that they feel the most nervous in English class. So when the teacher ask someone to answer questions in English class, the messages expressed by her eyes should be more encouraging, more soft, may be just "as warm as spring". Then students may feel more relaxed, get more selfconfidence and practice their oral English more freely and willingly. So as time going on, a warm atmosphere can come into being and the level of students' spoken English can be improved obviously.

\section{B. Space language in English classroom teaching}

Just as we communicate with words, gestures, or facial expressions, so too we transmit messages by playing us in certain spatial relationships with other persons or objects. The study of these spatial factors - how to react to the space around us, how we use the space, and how our use of space communicates certain information-is known as space language, or proxemics. The term proxemics comes from the Latin adjective "for near". It is typically broken down into the subcategories of personal space, touching and special arrangement. 


\section{1) The Use of Personal Space in English Classroom} Teaching

Teaching and learning in classroom are process of communication, and the spatial distance between teachers and students is a "critical factor in the communication process" (Miller, 1981). As for the message system, the focus on space between teachers and students is preferred, as it is the first fall upon the spatial distance between them. Generally, it is concerned with such things as our interpersonal distance and desk arrangement.

In most cases, the space between teachers and students is larger than that among students. Teachers' standing beside students to watch doing homework or taking test is regarded as invasion into students' territory in most Western cultures. Jeremy Harmer (2000) states that: "Some students resent it if the distance between them and the teacher is too small." In China, however, most students expect their teacher to move appropriately around the classroom instead of just standing at the very front between the blackboard and the platform. This indicates the teachers who-conduct their classes while standing or walking among their students is viewed more positively than those teachers who stand at the front of the classroom, these are seen as friendlier and are more effective than those who stand farther away from the students. "Students may feel more included and liked if the teacher stands in front of desk rather than using it as a separating barricade, and that students may focus more of their attention on the teacher, speak more, write more, and generally behave more in ways that the teacher approves" (Smith, 1984).

In the observation of the classroom activity, when a student gets absent-minded or does something irrelevant to the class, the teacher, if permitted, will move forward to the student if he or she does not want to interrupt the communication among other students. Under this circumstance, the thing noticed is that the students bring back his attention and resumes his classroom activity. So here comes an indication: the closer the teacher is to the student (up to 4 feet), the better the student responds both in attitude and in academic performance. If a teacher just stands behind the teacher's desk throughout the process of class, he neglects the fact that "motionless teachers can bore students...(Harmer, 2000)". Those teachers placing too much emphasis on their power figure in classroom fail to realize that the closeness of spatial distance can create such a relaxed atmosphere. Many Chinese teachers are accustomed to seeing students in the dormitory to show their care to them, which is normally welcomed by students. Moreover, Chinese students often go to teachers' home for a visit. However, Western people require more space. According to $\mathrm{Bi}$ Jiwan (1999), "American teachers do not go to students' dormitory and students dislike such kind of behavior." Only with the teachers' permission can students enter their offices, because Americans have more spaces that they consider their own, private places. Even though they may not own them, they have territorial rights to them, and if someone invades them, they could get quite upset. This different requirement of space between Chinese and Americans "is directly linked to the value system of culture. Cultures that stress individualism, such as that in American, generally demand more space than collective cultures do" (Samovar, 2000).

2) The Use of Touch in English Classroom Teaching Touch, as the most extreme reduction of individual distance, is one of our most primitive and yet sensitive ways of relating to others, and plays a significant role in giving encouragement, expressing tenderness, and showing emotional supports. It can be even more powerful than words sometimes, especially for establishing a link to students or conveying emotion. For example, when a student has just received some bad news, a pat on the shoulder from a teacher can be far more reassuring than many attempted words of understanding. However, where these touches are directed is critical. The shoulder and arm are the most acceptable body areas to have touched, especially for the boys, and the chest and legs the least, especially for the older girls. Back, head and hands are intermediate areas, but the head and hands, which are frequently touched by teachers of very young children, become less acceptable from ten or eleven onwards, especially for girls. As might be expected, all groups of children disliked angry types of touch, such as being hit or having their head twisted round, reinforcing the point made elsewhere that teachers should not use this form of aggression against children. A direct evidence of the effectiveness for touching the less little children in the classroom situation is available. It is not common for college teachers to touch college students. Similarly, most college students do not like teacher's touch, except for some necessary or particular situations such as encouraging touch combined with words, which would be more effective than verbal encouragement alone sometimes. The anthropologist Clements and Tracy's research shows that as to a small group of emotionally disturbed boys, encouragement touch, alone or combined with verbal encouragement, is more effective in improving their attention and performance. (Sean, 1991)

Though using touch has a lot of talus, the English teacher can use it to help teaching English in secondary school yet, apart from the traditional channels like listening, speaking, reading and writing. For example, in Unit 2 of the textbook "Go for it" published by People's Education Press, there are many new words about the parts of body, such as head, ear, eye, neck and leg etc., then the teacher can use a game named "touch and say" to teach these words. One student say a word optionally, another one must touch the corresponding parts of oneself immediately and exactly. This game can use the rule of elimination, that is to say, who can do the best at last. While playing this game, the students show great interests and learn the words quickly. This partly because this game caters to the teenager's emulative characteristic.

The attitudes concerning touch are different between Chinese and westerners at school. On Chinese campus, teachers often touch children's heads or pat children's shoulders to show their intimacy, warmth, affection and encouragement. Some college teachers tend to have the same behavior for the same purpose. But teachers seldom touch the students of older age or of the opposite sex. In America, teachers are less likely to touch students. The short novel "Hands" written by Sherwood Anderson, gives a typical example to prove what 
some American touch-avoidants are. The headmaster, named Adolph Myers, was exposed to a bad beat and finally driven by his students' parents from Pennsylvania town, just because the character "put his hands on his boy" (Bi, 1999).

\section{CONCLUSION}

Non-verbal communication is a main way of human communication. As the earth is becoming a global village at the present, the international communication is becoming more and more frequent and urgent, nonverbal behaviors are more and more important. However, for quite a long time both teachers and students tend to ignore the importance role of nonverbal behaviors in classroom teaching thus their NVC competence is far behind that in other countries just because they take them for granted, which is the main cause of the study of NVC being relatively short. This thesis attempts to provide a systematic analysis of how to improve the NVC competence of teachers and students in English classroom teaching. By presenting some uses of NVC such as the use of body language, space language and environment language during the English classroom teaching, the problem above would be greatly solved.

This thesis, however, still has some limitations and leaves some problems of studying nonverbal communication unexplored. For example, NVC varies a lot under different culture circumstance thus the ways for improving teachers and students' competence would be greatly changed. But in this thesis we had few discussion about it so further studies of this field will be put more and greater efforts later, because it is of great importance and benefit to study this aspect.

\section{REFERENCES}

[1] Aaron W. The Teacher and Nonverbal Behavior in the Multicultural Classroom. Burlington: Academic Press, 1979.

[2] Argly M. Body Communication. London: Methuen Press, 1998

[3] Cooper P. J. Speech Communication for the Classroom Teacher. Scottsdale: Gorsuch Scarisbrick Pub, 1988.

[4] Eakins. B. \& Eakins. G. Sex Difference in Human Communication. Boston: Houghton Mifflin College Div, 1978.

[5] Grant B.M. The Teacher Moves: An Analysis of Nonverbal Activity. New York: Teachers College Press, 1971.

[6] Harmer J. How to Teach English: Foreign Language Teaching and Research.

[7] New York: Teachers College Press, 2000.

[8] Harrison R. P. Beyond Words: An Introduction to Non-verbal Communication. Upper Saddle River: Prentice Hall Inc., 1974.

[9] Knapp M. \& J. A. Hall. Nonverbal Communication in Human Interaction. Belmont: Wadsworth Publishing, 2005.

[10] Knapp M. Interpersonal Communication and Human Relationships. Boston: Allyn \& Bacon, 1984.

[11] Malandro L. Nonverbal Communication. New York: AddisonWesley Publishing Company, 1983.

[12] Mehrabian A. Silent Messages: Implicit Communication of Emotions and Attitudes. Belmont: Wadsworth, 1983.

[13] Miller P.W. Nonverbal Communication. Washington, D. C: National Education Association, 1981.

[14] Samovar L. Communication between Cultures. Beijing: Foreign Language Teaching and Research Press, 2000.

[15] Sean N. Classroom Nonverbale Communication. London: Routledge, 1991 